\title{
DYNAMICS OF OXIDATIVE STATUS IN PATIENTS WITH PAROXYSMAL ATRIAL FIBRILLATION
}

\author{
${ }^{1}$ Mariya Negreva, ${ }^{1}$ Svetoslav Georgiev, ${ }^{2}$ Atanas Penev, ${ }^{3}$ Albena Alexandrova \\ ${ }^{1}$ Department of Cardiology, Medical University of Varna, \\ ${ }^{2}$ Associate Professor, Department of Cardiology, Medical University of Varna, \\ ${ }^{3}$ Associate Professor, Laboratory of Free Radical Processes, \\ Institute of Neurobiology, Bulgarian Academy of Science
}

\begin{abstract}
INTRODUCTION: Studies have established oxidative disorders in persistent and permanent atrial fibrillation. Our aim was to investigate oxidative status still in the early hours of paroxysmal atrial fibrillation (PAF) and monitor its changes after sinus rhythm (SR) restoration.

MATERIAL AND METHODS: Levels of malondialdehyde and total glutathione were determined in plasma (PI-MDA; Pl-GSH) and erythrocytes (Er-MDA; Er-GSH) together with erythrocyte glutathione peroxidase activity (GSH-Px) in 51 patients (59.84 \pm 1.6 years, 26 males). Markers were investigated upon hospital admission, 24 hours and 28 days after SR restoration. They were also determined in $\mathbf{5 2}$ healthy subjects (59.50 \pm 1.46 years, 26 males).

RESULTS: Mean AF duration prior to hospitalization was 8.14 \pm 0.76 hours. Upon admission, Pl-MDA and Er-MDA were significantly increased $(\mathbf{p}<0.05 ; \mathbf{p}<0.001)$, while PI-GSH, Er-GSH and GSH-Px - decreased $(\mathbf{p}<\mathbf{0 . 0 0 1})$. Twenty four hours after rhythm conversion, changes in Er-MDA $(\mathbf{p}<0.001), \mathrm{Pl}-\mathrm{GSH}, \mathrm{Er}-\mathrm{GSH}$ and GSH-Px $(p<0.05)$ were retained. On the $28^{\text {th }}$ day, there was no significant difference in any of the markers $(\mathrm{p}>0.05)$.

CONCLUSION: Disorder of oxidative status is detected in the early hours of PAF, which persists after SR restoration. Oxidative balance is restored slowly with time. This specific dynamics of oxidative status is most likely related to AF clinical course, namely to its manifestation and recurrences.
\end{abstract}

Keywords: atrial fibrillation, malondialdehyde, glutathione, glutathione peroxidase, sinus rhythm

\section{INTRODUCTION}

Atrial fibrillation (AF) is the most common arrhythmia in clinical practice, affecting $1-2 \%$ of the total population (1). It is a significant public health

\footnotetext{
Address for correspondence:

Mariya Negreva

Department of Cardiology

Medical University of Varna

e-mail:mnegreva@abv.bg
}

Received: August 30, 2014

Accepted: September 10, 2014 problem as its manifestation is associated with deteriorated quality of life, increased incidence of thromboembolic accidents and increased risk of cardiovascular mortality (2-4). In spite of the considerable body of investigations, the mechanisms determining the clinical course of arrhythmia are not fully clarified (5).

In recent years more and more evidence has been accumulated concerning the possible role of oxidative stress in the development of AF. The histological studies have established oxidative changes in the myocardium both by experimental models and in patients with AF (6-10). Increased levels of oxidative markers were measured in patients with persistent and permanent AF (11-13). It was established 
that these changes were due to the presence of the rhythm disorder $(14,15)$. Changes in the gene expression profile were also proved (16). However, clinical in vivo studies lack, investigating oxidative status in the early hours of AF manifestation and following its changes after the restoration of sinus rhythm (SR).

It is known that oxidative status depends simultaneously on the levels of oxidative processes and antioxidant defense system (17). Lipid biomolecules, polyunsaturated fatty acids, in particular, are extremely susceptive to the action of reactive oxygen species (ROS) (18). Therefore, the products of lipid peroxidation are frequently used biomarkers in the assessment of oxidative damages in vivo (19). One of the main products of secondary lipid decomposition is malondialdehyde (MDA) (20). This turns it into a common marker of the assessment of oxidative processes in the human organism.

An important component of the complex antioxidant defense system of the organism is glutathione (GSH). High electron-donating capacity in combination with high intracellular concentration determines the considerable reduction power of GSH (21). In essence, it is a "key" nonenzyme antioxidant for the organism (22). Although it is relatively resistant to "spontaneous oxidation", GSH can directly react with hydroxyl radicals and peroxynitrites and neutralize them (23). Furthermore, it is an obligatory cofactor of one of the major antioxidant enzymes glutathione peroxidase (GSH-Px) (22). In its presence GSH-Px catalyzes the reduction of hydrogen peroxide and organic hydroperoxides to water or the corresponding alcohols (24). The system GSH/GSH-Px is crucial for the condition of antioxidant defense system in the human organism $(22,25-27)$.

All the above determined both the aim of our study and the investigated markers.

\section{AIM}

To study in dynamics the oxidative status of patients with paroxysmal atrial fibrillation (PAF) (arrhythmia duration $<48$ hours) by monitoring the plasma and erythrocyte levels of MDA (Pl-MDA; ErMDA) and total GSH (Pl-GSH; Er-GSH) as well as the activity of the enzyme GSH-Px in the erythocytes.

\section{MATERIAL AND METHODS}

\section{Study population}

The study was conducted at the Intensive Cardiac Care Unit of the First Clinic of Cardiology at University Hospital „St. Marina“ - Varna for the period from October 2010 to May 2012 following the approval of the Scientific Research Ethical Commission at the hospital and in accordance with the requirements of the Helsinki Declaration (28).

The participants were included in the study after having signed the informed consent form for participation.

For the purposes of the study, patients with PAF, only with a history of arrhythmia $<48$ hours, were screened which could allow for an acute medication attempt to restore SR. Out of 338 patients, 259 patients had to be excluded from the study (see exclusion criteria). The criterion for the establishment of the duration of the rhythm disorder was the taking of a detailed history, in which the patients determined the onset of the AF episode according to the subjective feeling of "palpitation" continuing up to the moment of hospitalization. The electrocardiographic investigations performed immediately after hospitalization and the monitoring were used as a confirmation of the diagnosis.

In order to restore SR, propafenone was administered in all the remaining 79 patients according to the established scheme, namely i.v. $2 \mathrm{mg} / \mathrm{kg}$ bolus, followed by infusion in a dose $0.0078 \mathrm{mg} / \mathrm{kg} / \mathrm{min}$ for $120 \mathrm{~min}$. If the rhythm disorder persisted, the treatment with propafenone continued p.o. in a dose 300 $\mathrm{mg}$ three times at an interval of 8 hours $(29,30)$. The total duration of the applied scheme for SR recovery with propafenone was maximum 24 hours, within which SR was registered in 56 of the participants in the study ( 31 male, 25 female). Until the end of the study (28 days after recovery of the rhythm) all the 56 patients took p.o. propafenone $150 \mathrm{mg}$ three times daily as maintenance dose. AF recurrences were not observed.

After having equalized the gender structure of the patients' group, 51 patients ( 26 male и 25 female) of mean age $59.84 \pm 1.60$ years (31-77 years) were selected for the study. 
Mariya Negreva, Svetoslav Georgiev, Atanas Penev et al.

There are no literary data so far about the impact of propafenone on the oxidative status of patients with AF.

A control group was formed identical to the patients' group in terms of the factors for which it is known that influence oxidative status, namely: gender, age (in decades), body mass index (BMI), deleterious habits as well as in terms of accompanying diseases and the treatment administered for them. Out of 169 screened healthy subjects (controls), 52 were selected for the study. The mean age of the controls was $59.50 \pm 1.46$ years ( $30-76$ years), males and females being of equal number - 26 (50\%). The controls had no history or electrocardiographic evidence of AF.

The following exclusion criteria for the study participation were used:

1. Cardiovascular diseases, namely: ischaemic heart disease, chronic heart failure, resistent hypertension, implanted devices for the treatment of rhythm conductive disorders, imflammatory or congenital heart diseases, moderate or severe acquired valve diseases, cardiomyopathies;

2. Other diseases - renal or hepatic failure, diseases of the central nervous system, imflammatory or infectious diseases for the previous threee months, neoplastic or autoimmune diseases, chronic lung diseases, diseases of the endocrine system (except for diabetes mellitus type 2, noninsulin dependent, well controlled);

3. Intake of hormone replacement therapy, contraceptives, systemic intake of analgesics, including nonsteroid antiinflammatory drugs;

4. Impossibility for the patients to determine the onset of the arrhythmia;

5. Persistent rhythm disorder after the $24^{\text {th }}$ hour scheme of propafenone; restoration of SR by means of electrical cardioversion; AF recurrences until the end of the study.

\section{Obtaining erythrocytes and plasma}

In patients with PAF, blood samples were taken three times a day, immediately after hospitalization in the ward (baseline values), on the $24^{\text {th }}$ hour and on the $28^{\text {th }}$ day after the recovery of SR. The choice of the $28^{\text {th }}$ day for the end of the monitoring was determined after the preliminary study conducted by us. The blood samples of the controls were taken once.

Plasma and erythrocytes were obtained from $4 \mathrm{ml}$ venous blood collected in a heparin vacutainer (Vacuette/4.0 ml/Li Hep). The blood was centrifuged at $4^{\circ} \mathrm{C}$ at $600 \mathrm{~g}$ for $10 \mathrm{~min}$. The obtained plasma was removed from the erythrocytes and placed in a plastic test tube. Erythrocytes were washed twice with $0.9 \%$ sodium chloride and were centrifuged under the same conditions. The obtained erythrocyte suspension and plasma were frozen at $-70^{\circ} \mathrm{C}$ and stored at this temperature up to six months for biochemical analysis.

3. Determination of MDA and GSH level in plasma and erythrocytes. GSH-Px activity determination

Lipid peroxidation was determined by the amount of thiobarbituric acid reactive substances formed in erythrocytes (31). Erythrocyte suspension $(0.5 \%$, according to $\mathrm{Hb})$ in the presence and in the absence of $10 \mathrm{mM} \mathrm{H}_{2} \mathrm{O}_{2}$, as well as plasma (mg protein/ml), both in $0.15 \mathrm{M} \mathrm{NaCl}-10 \mathrm{mM}$ sodium phosphate buffer, $\mathrm{pH} 7.2$ were incubated for 60 minutes at $37^{\circ} \mathrm{C}$. The absorbance was read at $532 \mathrm{~nm}$ against appropriate blanks; $\mathrm{A}_{600}$ was considered to be a nonspecific baseline and was subtracted from $A_{532}$. Values were expressed in nmoles MDA per mg protein (for plasma) and in nmoles MDA per mg Hb (for erythrocytes), with a molar extinction coefficient of $1.56 \times 10^{5} \mathrm{M}^{-1} \mathrm{~cm}^{-1}$.

Pl-GSH and Er-GSH were measured according to Tietze (32). The absorbance was read at $412 \mathrm{~nm}$; values were expressed in $\mathrm{ng} / \mathrm{mg}$ protein (for plasma) and $\mathrm{ng} / \mathrm{mg} \mathrm{Hb}$ (for erythrocytes), with glutathione oxidized (GSSG) as reference standard.

GSH-Px activity in erythrocytes was measured by the method of Gunzler et al (33) and was expressed in nmoles NADPH oxidized per minute per mg $\mathrm{Hb}$, with a molar extinction coefficient of $6.22 \times 10^{6} \mathrm{M}^{-1} \mathrm{~cm}^{-1}$.

Every sample was investigated three times, the obtained results having a high degree of repetitiveness ( $p>0.001)$; the mean value from the three measurements was taken into consideration. The samples sent to the laboratory were coded which did not allowed the researcher to have access to the informa- 
tion about the belonging of the sample (control or patient) or the date of its obtaining.

\section{Statistical analysis of the results.}

The statistical processing of the results was performed by the GraphPad Prism 4 software. Descriptive statistics was used for the calculation of indicators for relative share, mean values, standard error of the mean (SEM) and central tendency (Mo). The analysis of hypotheses has been performed by means of Student's t-criteria for comparing mean values and indicators of relative share at reliability level 0.95 (levels $\mathrm{p}<0.05$ are considered statistically significant). All results were presented as a mean value \pm SEM.

\section{RESULTS}

\section{Patients' characteristics}

The characteristics of the patients and the controls are presented in Table 1. In terms of the indicators for number, mean age and gender structure, the patients' group was comparable to that of the control ( $p>0.05)$. In terms of the indicators for hypertension, diabetes mellitus, dyslipidemia and the administered treatment for them as well as those for current smoking and alcohol intake, body mass index (BMI) and the measured echocardiographic indicators, the group of patients with PAF was styatistically identical with that of the control group ( $p>0.05)$.

According to the data from the history taking, the mean duration of the AF episodes up to the time of hospitalization was $8.14 \pm 0.76$ hours, the patients being most frequently hospitalized on the $5^{\text {th }}$ hour from the onset of the arrhythmia $(\mathrm{Mo}=5$ hours; 10 patients out of all 51 patients). None of the patients was hospitalized after the $24^{\text {th }}$ hour.

2. Levels of lipid peroxidation in the plasma and the erythrocytes

Figure 1 shows that Pl-MDA levels upon admission to the ward were elevated as compared to those of the controls $(0.143 \pm 0.007$ vs $0.125 \pm 0.004$ $\mathrm{nmol} / \mathrm{mg}$ protein, $\mathrm{p}<0.05)$. Twenty four hours after the restoration of SR, the measured values of $\mathrm{Pl}$ MDA were decreased and did not statistically differ from Pl-MDA levels of the controls $(0.125 \pm 0.005$ vs $0.125 \pm 0.004 \mathrm{nmol} / \mathrm{mg}$ protein, $\mathrm{p}>0.05$ ). Twenty-eight days after rhythm normalization, the results again showed lack of a significant difference with the con- trols $(0.117 \pm 0.004$ vs $0.125 \pm 0.004 \mathrm{nmol} / \mathrm{mg}$ protein, $\mathrm{p}>0.05)$.

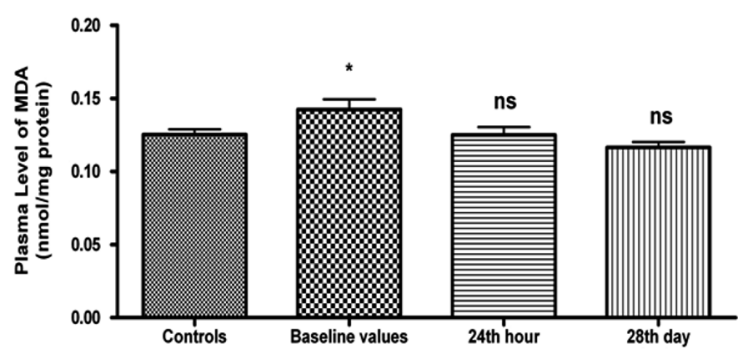

Fig. 1. Dynamics in Pl-MDA levels (nmol/mg protein) in patients with PAF

${ }^{*}-p<0.05 ; n s-$ statistically insignificant difference)

The results presented in Fig. 2 indicate elevated baseline values of Er-MDA levels in patients as compared to the controls $(1.368 \pm 0.069$ vs $0.386 \pm 0.027$ $\mathrm{nmol} / \mathrm{mg} \mathrm{Hb}, \mathrm{p}<0.001)$. Twenty four hours after recovery of SR Er-MDA values were significantly higher $(0.916 \pm 0.047$ vs $0.386 \pm 0.027 \mathrm{nmol} / \mathrm{mg} \mathrm{Hb}$, $\mathrm{p}<0.001)$. On the $28^{\text {th }}$ day, the Er-MDA levels in patients did not statistically differ from the controls $(0.419 \pm 0.039$ vs $0.386 \pm 0.027 \mathrm{nmol} / \mathrm{mg} \mathrm{Hb}, \mathrm{p}>0.05)$.

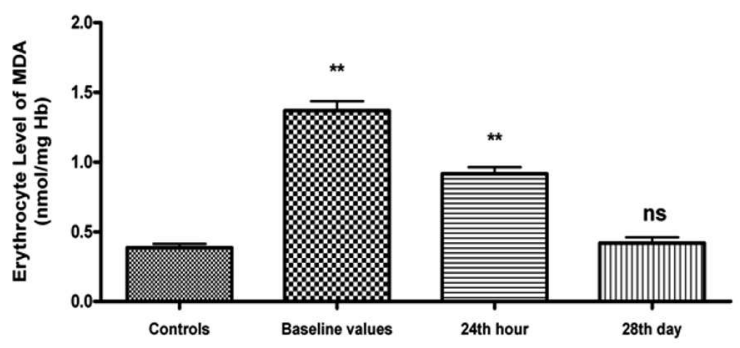

Fig. 2. Dynamics of Er-MDA levels ( $\mathrm{nmol} / \mathrm{mg} \mathrm{Hb}$ ) in patients with $P A F$

${ }^{* *}-p<0.001 ;{ }^{*}-p<0.05 ; n s-$ statistically insignificant difference)

\section{Total GSH levels in plasma and erythrocytes}

The patients' total Pl-GSH values upon hospitalization (Fig. 3) were lower as compared to those in the controls $(64.97 \pm 1.28$ vs $75.00 \pm 1.39 \mathrm{ng} / \mathrm{mg}$ protein, $\mathrm{p}<0.001)$. Measured twenty four hours after the restoration of SR, they continued to be significantly lower $(68.78 \pm 1.32$ vs $75.00 \pm 1.39 \mathrm{ng} / \mathrm{mg}$ protein, $\mathrm{p}<0.05)$. On the $28^{\text {th }}$ day after the normalisation of the rhythm, Pl-GSH values in patients did not statis- 


\section{Patients with PAF}

Number of participants in the group

Age (years)

Men/Women

Cardiovascular risk factors

Hypertension

Diabetes mellitus type 2

Dyslipidemia

Smoking*

Alcohol intake

Body Mass Index (BMI)

Medicaments for Hypertension and Dyslipidemia

Beta blockers

ACE inhibitors

Sartans

Statins

Echocardiographic measurements

LVEDD mm

LVEF\%

LA volume $\mathrm{ml} / \mathrm{m}^{2}$
51

$59.84 \pm 1.60$

$26 / 25$

$37(72.5 \%)$

$3(5.9 \%)$

$4(7.8 \%)$

$8(15.7 \%)$

$7(13.7 \%)$

$23.85 \pm 0.46 \mathrm{~kg} / \mathrm{m}^{2}$

$19(37.3 \%)$

15 (29.4\%)

$11(21.6 \%)$

$4(7.8 \%)$

$52.57 \pm 0.58$

$52.29 \pm 0.57$

$62.98 \pm 0.70$

$22.81 \pm 0.45$
Control group

52

$59.50 \pm 1.46$

$26 / 26$

$34(65.4 \%)$

7(13.5\%)

$6(11.5 \%)$

$24.95 \pm 0.45 \mathrm{~kg} / \mathrm{m}^{2}$

17(32.7\%)

14(26.9\%)

9(17.3\%)

$3(5.8 \%)$

LA: left atrium; LVEF: left ventricular ejection fraction: LVEDD: left ventricular end-diastolic volume.

*The smokers did not smoke more than half a packet weekly. The hospitalized patients had not smoked minimum 24-48 hours before the onset of arrhythmia. The investigations of the controls and those on the 28th day after dehospitalisation were performed after a 48hour period free of smoking.

${ }^{*}$ No more than 1-2 drinks/weekly. The hospitalized patients had not consumed alcohol for a minimum of 48 hours before the onset of arrhythmia. The investigations of the controls and those on the 28th day after dehospitalisation were performed after a 48-hour period without alcohol consumption.

tically differ from those in the controls $(73.96 \pm 1.93 \mathrm{vs}$ $75.00 \pm 1.39 \mathrm{ng} / \mathrm{mg}$ protein, $\mathrm{p}>0.05)$.

Baseline values of Er-GSH in patients with PAF (Fig. 4) were significantly decreased $(997.00 \pm 32.60$ vs $1347.00 \pm 32.61 \mathrm{ng} / \mathrm{mg} \mathrm{Hb}, \mathrm{p}<0.001)$. Twenty four hours after rhythm regularization, they were still lower $(1215.00 \pm 46.71$ vs $1347.00 \pm 32.61 \mathrm{ng} / \mathrm{mg} \mathrm{Hb}$, $\mathrm{p}<0.05)$. On the twenty eight day, values of Er-GSH did not differ from that of the controls $(1321.00 \pm 44.57$ vs $1347.00 \pm 32.61 \mathrm{ng} / \mathrm{mg} \mathrm{Hb}, \mathrm{p}>0.05)$.

\section{Activity of GSH-Px in erythrocytes}

Upon hospital admission, GSH-Px activity in erythrocytes (Fig. 5) was significantly decreased $(25.00 \pm 0.81$ vs $30.11 \pm 0.85 \mathrm{nmol} / \mathrm{min} / \mathrm{mg} \mathrm{Hb}$, $\mathrm{p}<0.001)$. Twenty four hours after SR restoration, the lower enzyme activity persisted $(27.20 \pm 1.04$ vs $30.11 \pm 0.85 \mathrm{nmol} / \mathrm{min} / \mathrm{mg} \mathrm{Hb}, \mathrm{p}<0.05$ ), while on the twenty eight day no significant difference was established $(30.72 \pm 0.67$ vs $30.11 \pm 0.85 \mathrm{nmol} / \mathrm{min} / \mathrm{mg} \mathrm{Hb}$, $\mathrm{p}>0.05)$. 


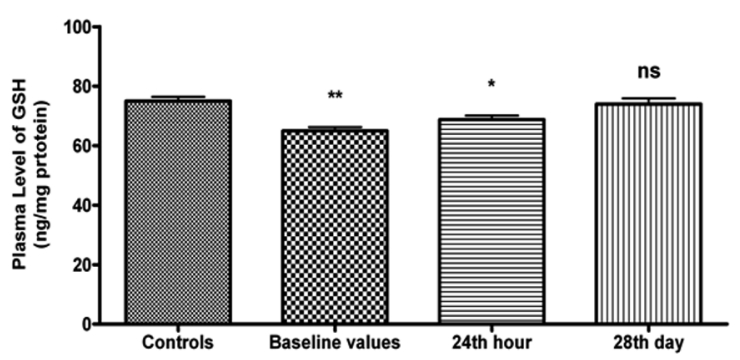

Fig. 3. Dynamics in Pl-GSH levels ( $\mathrm{ng} / \mathrm{mg}$ protein) in patients with $P A F$

${ }^{* *}-p<0.001{ }^{*}-p<0.05 ; n s-$ statistically insignificant difference)

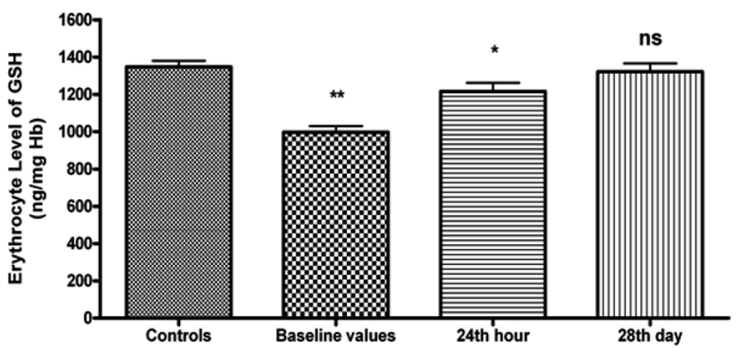

Fig. 4. Dynamics in Er-GSH levels (ng/mg protein) in patients with PAF

$\left({ }^{*}-p<0.001{ }^{*}-p<0.05 ; n s-\right.$ statistically insignificant difference)

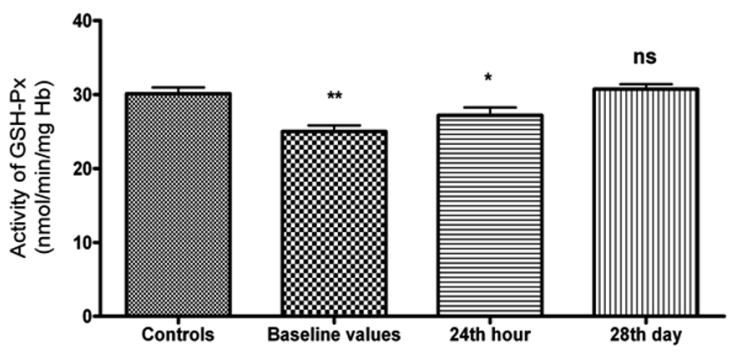

Fig. 5. Dynamics in GSH-Px activity (nmol/min/mg Hb) in erythrocytes in patients with $P A F$.

$\left({ }^{*}-p<0.001 ;{ }^{*}-p<0.05 ; n s-\right.$ statistically insignificant difference)

\section{DISCUSSION}

The results from our study demonstrated that the values of all markers, measured upon patients' admission to the ward, differ significantly from those of the controls (Fig. 1-5). MDA levels both in plasma and in erythrocytes were higher than those in the controls (Fig. 1, 2). As we have already mentioned MDA is one of the most common markers of lipid peroxidation. The elevated values provide information about enhanced oxidative damage of lipid biomolecules and are an indirect sign of increased levels of ROS $(34,35)$. With these facts in mind, the results obtained by us give grounds to assume that early (still up to the $24^{\text {th }}$ hour) in the clinical manifestation of PAF, enhanced oxidative processes are present.

Baseline values of the investigated antioxidants also differed significantly from those measured in the controls (Fig. 3-5). The levels of total Er-GSH, $\mathrm{Pl}-\mathrm{GSH}$ and the activity of GSH-Px in erythrocytes were considerable lowered. The total GSH in blood is a good indicator of oxidative status [19], its low values manifesting a lowered level of the nonenzyme antioxidant system. It is known that an early sign of a change in the oxidative balance is GSH-Px, its decreased activity being a manifestation of a reduced potential of the enzyme antioxidant system. Therefore, our results for baseline values of Er-GSH, PlGSH and GSH-Px indicated a decreased potential for eliminating ROS, respectively reduced antioxidant defense system.

Summarizing the results till now, we may conclude that still in the early hours (up to the $24^{\text {th }}$ hour) of AF clinical manifestation, disbalance of oxidative status is observed. Oxidative stress develops as a result of enhanced oxidative processes and reduced defense antioxidant mechanisms. The early manifestation of these disorders enables us to assume that they are most likely associated with the initiation of AF.

The oxidative status in PAF has been subject to other studies, too. Wy et al. established significantly increased levels of serum MDA and reduced activity of superoxide dismutase (36). The fact must be noted that these changes in oxidative status, unlike our results, were registered in much later hours from the onset of the disease - up to the seventh day. Considerably greater in number are experimental studies. Pacing of in vitro differentiated cardiomyocytes caused a significant decrease in intracellular contents of thioles (9). The induction of arrhythmia in experimental models led to a decrease in ascorbate level and elevation of 3-Nitrotyrosine in the atrial tissue [8], increased production of superoxide onions (37), up-regulation of NADPH oxidases (Nox 2/4) and $\operatorname{Racl}(7,38)$. In essence, these results are extremely important but as it is known that the condition in the experimental models are not identical with those in the human organism. 
Mariya Negreva, Svetoslav Georgiev, Atanas Penev et al.

The results obtained 24 hours after the arrhythmia discontinuation are specific in their nature. The values of four out the five studied markers still differed statistically from those in the controls - levels of Er-MDA were still significantly higher (Fig. 2) and the values of Pl-GSH, Er-GSH and GSH-Px remained low (Fig. 3-5). In spite of the restored SR, processes of lipid peroxidation in erythrocytes remained enhanced and antioxidant defense system - with lowered activity. The persistence in these changes leads us to the conclusion that the oxidative status of patients with PAF is disordered not only during the clinical manifestation of arrhythmia but also afterwards. The impact of enhanced oxidative processes on the organism and on the cardiovascular system in particular continues after the arrhythmia episode, too. A number of studies have demonstrated a possible relation between oxidative status and structural remodeling of the atria (39-44). Data are available confirming that atrial remodeling is associated with the manifestation and the retention of AF (45-47). Consequently, the persistence of changes in oxidative status established by us after the recovery of SR are very important for the clinical course of $\mathrm{AF}$ and are most likely related to the arrhythmia recurrences.

Noteworthy, Pl-MDA values did not differ statistically from those in the control group (Fig. 1), unlike the values of the same marker measured in the erythrocytes (Fig. 2). This result could be explained with the fact that erythrocytes are more susceptible to oxidative damage due to high contents of polyunsaturated fatty acids in their cell membrane and increased concentration of oxygen $(48,49)$.

The results obtained 28 days after SR recovery are particularly interesting. Between patients and controls there was no statistically significant difference in any of the investigated markers (Fig. 1-5). The analysis of these results indicates that oxidative balance in the patients' group was restored. A decrease was observed in the activity of prooxidant system (Fig. 1, 2) and elevated levels of the antioxidant defense system (Fig. 3-5) during the studied period following SR recovery. These processes occur relatively slowly in time (up to the $28^{\text {th }}$ day) which predetermines the continuous effect of the enhanced oxidative processes on the organism.
It is noteworthy that during the period of the study, in the patients with PAF was initiated no treatment with medications that influence oxidative status of the organism. This is an argument for us to consider that the restoration of oxidative balance is a result of endogenous regulatory mechanisms such as the involvement of the endocrine system (50). As far as in the course of our study disorders in prooxidant and antioxidant system were present, we are of the opinion that their simultaneous therapeutic influence is expedient.

\section{CONCLUSION}

In conclusion, the oxidative stress develops still in the early (up to $24^{\text {th }}$ hour) of PAF, with simultaneously significantly increased prooxidant activity and decreased levels of antioxidant defense system. These changes persist after the recovery of SR and oxidative balance is restored gradually with time. This specific dynamics in oxidative status is probably closely related to the clinical course of the disease, namely to its manifestation and recurrences.

\section{Acknowledgments}

None of the authors and/or executors of this research have any potential conflict of interests to declare. No grants or funds were financially involved in the research.

\section{REFERENCES}

1. Go AS, Hylek EM, Phillips KA, Chang Y, Henault LE, Selby JV, et al. Prevalence of diagnosed atrial fibrillation in adults: national implications for rhythm management and stroke prevention: the AnTicoagulation and Risk Factors in Atrial Fibrillation (ATRIA) Study. JAMA 2001;285:2370-2375.

2. Stewart S, Hart CL, Hole DJ, McMurray JJ. A population-based study of the long-term risks associated with atrial fibrillation: 20 -year followup of the Renfrew/Paisley study. Am J Med 2002;113:359-364.

3. Knecht $S$, Oelschlager C, Duning T, Lohmann $\mathrm{H}$, Albers J, Stehling C, et al. Atrial fibrillation in stroke-free patients is associated with memory impairment and hippocampal atrophy. Eur Heart J 2008;29:2125-2132.

4. Thrall G, Lane D, Carroll D, Lip GY. Quality of life in patients with atrial fibrillation: a systematic review. Am J Med 2006;119:448 e1-e19. 
5. Aldhoon B, Melenosky V, Peichl P, Kautzner J. New insights into mechanisms of atrial fibrillation. Physiol Res. 2010;59(1):1-12.

6. Mihm MJ, Yu F, Carnes CA, Reiser PJ, McCarthy PM, Van Wagoner DR, et al. Impaired myofibrillar energetics and oxidative injury during human atrial fibrillation. Circulation 2001;104:174-80.

7. Yeh YH, Kuo CT, Chan TH, Chang GJ, Qi XY, Tsai F, Nattel S,et al. Transforming growth factor-beta and oxidative stress mediate tachycardia-induced cellular remodelling in cultured atrial-derived myocytes. Cardiovasc Res 2011;91:62-70.

8. Carnes CA, Chung MK, Nakayama T, Nakayama $\mathrm{H}$, Baliga RS, Piao S, et al. Ascorbate attenuates atrial pacing-induced peroxynitrite formation and electrical remodeling and decreases the incidence of postoperative atrial fibrillation. Circ Res. 2001;89(6):E32-8.

9. Schild L, Bukowska A, Gardemann A, Polczyk P, Keilhoff G, Täger M,et al. Rapid pacing of embryoid bodies impairs mitochondrial ATP synthesis by a calcium-dependent mechanism--a model of in vitro differentiated cardiomyocytes to study molecular effects of tachycardia. Biochim Biopsy Acta. 2006;1762(6):608-15.

10. Kim YM, Guzik TJ, Zhang YH, Zhang MH, Kattach $\mathrm{H}$, Ratnatunga C, et al. A myocardial Nox 2 containing $\mathrm{NAD}(\mathrm{P}) \mathrm{H}$ oxidase contributes to oxidative stress in human atrial fibrillation. Circ Res 2005;97:629-36.

11. Toyama K, Yamabe H, Uemura T, Nagayoshi $Y$, Morihisa K, Koyama J, et al. Analysis of oxidative stress expressed by urinary level of 8-hydroxy-2'deoxyguanosine and biopyrrin in atrial fibrillation: effect of sinus rhythm restoration. Int J Cardiol 2013;168(1):80-5.

12. Leftheriotis DI, Foutoulaki KT, Flevari PG, Parissis JT, Panou FK, Andreadou IT, et al. The predictive value of inflammatory and oxidative markers following the successful cardioversion of persistent lone atrial fibrillation. Int J Cardiol 2009;135(3):361-9.

13. Neuman RB, Bloom HL, Shukrullah I, Darrow LA, Kleinbaum D, Jones DP, et al. Oxidative stress markers are associated with persistent atrial fibrillation. Clin Chem. 2007; 53(9):1652-1657.

14. Kim YM, Kattach H, Ratnatunga C, Pillai R, Channon KM, Casadei B. Association of atrial nicotinamide adenine dinucleotide phosphate oxidase activity with the development of atrial fibrillation after cardiac surgery. J AmColl Cardiol 2008;51:68-74.

15. Antoniades $\mathrm{C}$, Demosthenous $\mathrm{M}$, Reilly $\mathrm{S}$, Margaritis M, Zhang MH, Antonopoulos A, et al. Myocardial redox state predicts in-hospital clinical outcome after cardiac surgery effects of short-term pre-operative statin treatment. J Am Coll Cardiol 2012;59(1):60-70.

16. Kim YH, Lin DS, Lee JH, Shim WJ, Ro YM, Park $\mathrm{GH}$, et al. Gene expression profiling of oxidative stress on atrial fibrillation in humans. Exp Mol Med 2003;35(5):336-49.

17. Poljsak B, Šuput D and Milisav I. Achieving the Balance between ROS and Antioxidants: When to Use the Synthetic Antioxidants. Oxid Med Cell Longev 2013, Article ID 956792.

18. Niki E. Lipid peroxidation products as oxidative stress biomarkers. Biofactors. 2008;34(2):171-80.

19. Dalle-Donne I, Rossi R, Colombo R, Giustarini D, Milzani A. Biomarkers of Oxidative Damage in Human Disease. Clin Chem 2006;52:4;601-623.

20. Shilpa HD, Bijoor AR. Malondialdehyde as a marker of lipid peroxidation in acute myocardial infarction patients. MRIMS. J Health Sci 2013;1(1):20-22.

21. Parris M. Glutathione K. Systemic Protectant Against Oxidative and Free Radical Damage. Alt Med Rev 1997; 2(3):155-176

22. Lushchak VI. Glutathione Homeostasis and Functions: Potential Targets for Medical Interventions. Journal of Amino Acids Volume 2012, Article ID 736837, 26 pages

23. Griffith OW. Biologic and pharmacologic regulation of mammalian glutathione synthesis. Free Radical Biol Med 1999; 27(9-10):922-35.

24. Brigelius-Flohe R, Maiorino M. Glutathione peroxidases. Biochimica et Biophysica Acta 2013;1830:3289-3303.

25. Miyamoto Y, Koh YH, Park YS, Fujiwara N, Sakiyama H, Misonou Y, et. al. Oxidative stress caused by inactivation of glutathione peroxidase and adaptive responses. Biol Chem 2003;384(4):567-74.

26. Haayes JD, McLellan LI. Glutathione and glutathione-dependent enzymes represent a coordinately regulated defence against oxidative stress. Free Radical Research, 1999; 31(4):273-300. 
Mariya Negreva, Svetoslav Georgiev, Atanas Penev et al.

27. Wu G, Fang Y-Z, Yang S, Lupton JR, Turner ND. Glutathione Metabolism and Its Implications for Health. J. Nutr 2004;134(3):489-492.

28. World Medical Association Declaration of Helsinki. Ethical principles for medical research involving human subjects. 59th WMA General Assembly. Seoul. 2008.

29. Bellandi F, Cantini F, Pedone T, Palchetti R, Bamoshmoosh M, Dabizzi RP. Effectiveness of intravenous propafenone for conversion of recentonset atrial fibrillation: a placebo-controlled study. Clin Cardiol. 1995;18:631-634.

30. Bianconi L, Mennuni M. Comparison between propafenone and digoxin administered intravenously to patients with acute atrial fibrillation. Am J Cardiol 1998;82:584-588.

31. Gilbert S., Strump DD, Roth EF. A method to correct errors caused by generation of interfering compounds during erythrocyte lipid peroxidation. Anal Biochem 1984;137:282-286.

32. Tietze, F. Enzymaticmethod for quantitative determination of nanogram amounts of total and oxidized glutathione: applications to mammalian blood and other tissues. Anal Biochem 1969;27:502-522.

33. Gunzler WA, Vergin H, Muller I, Flohe L. Glutathion peroxidase. VI. Die reaction der glutathion peroxidase mit Verschieden hydroperoxiden. Hoppe-Seyler's Z Physiol Chem 1972;353:1001-1004.

34. Del Rio D, Stewart AJ, Pellegrini N. A review of recent studies on malondialdehyde as toxic molecule and biological marker of oxidative stress Nutrition. Metab Cardiovasc Dis 2005;15:316e328.

35. Lykkesfeldt J. Malondialdehyde as biomarker of oxidative damage to lipids caused by smoking. Clin Chim Acta 2007;380(1-2):50-58.

36. Wu Y, Zhang K, Zhao L, Guo J, Hu X, Chen Z. Increased serum HMGB1 is related to oxidative stress in patients with atrial fibrillation. J Int Med Res 2013;41(6):1796-802.

37. Dudley SC Jr, Hoch NE, McCann LA, Honeycutt C, Diamandopoulos L, Fukai T, et al. Atrial fibrillation increases production of superoxide by the left atrium and left atrial appendage: role of the NADPH and xanthine oxidases. Circulation 2005;112(9):1266-73.

38. Adam O, Frost F, Sussman MA, Schaefers HJ, Boehm M, Laufs U. Role of Rac1 GTPase activation in atrial fibrillation. J Am Coll Cardiol 2007;50(4):359-67.

39. Matsuzawa A, Ichijo H. Stress-responsive protein kinases in redox-regulated apoptosis signaling. Antioxid Redox Signal 2005;7:472-81.

40. Saito K, Ishizaka N, Aizawa T, Ohno M, Nagai R. Iron chelation and a free radical scavenger suppress angiotensin II-induced upregulation of TGF-betal in the heart. Heart Circ Physiol 2005;288:H183643 DOI: 10.1152/ajpheart.00679.2004

41. Hanna N, Cardin S, Leung TK, Nattel S. Differences in atrial versus ventricular remodeling in dogs with ventricular tachypacing-induced congestive heartfailure. Cardiovasc Res 2004;63:236-44.

42. Lee KW, Everett TH, Rahmutula D, Guerra JM, Wilson E, Ding C, et al. Pirfenidone prevents the development of a vulnerable substrate for atrial fibrillation in a canine model of heart failure. Circulation 2006;114:1703-12.

43. Nattel S, Shiroshita-Takeshita A, Cardin S, Pelletier P. Mechanisms of atrial remodeling and clinical relevance. Curr Opin Cardiol 2005;20:21-5.

44. Miragoli M, Salvarani N, Rohr S. Myofibroblasts induce ectopic activity in cardiac tissue. Circ Res 2007;101:755-8.

45. Nattel S, Burstein B, Dobrev D. Atrial Remodeling and Atrial Fibrillation: Mechanisms and Implications Circ Arrhythm Electrophysiol 2008;1:62-73.

46. Everett TH, Olgin JE. Atrial fibrosis and the mechanisms of atrial fibrillation. Heart Rhythm 2007; 4(Suppl 3):S24-S27.

47. Casaclang-Verzosa G, Gersh BJ, Tsang TSM. Structural and functional remodeling of the left atrium. Clinical and therapeutic implications for atrial fibrillation. J Am Coll Cardiol 2008;51(1):1-11.

48. Pandey KB, Rizvi SI. Biomarkers of oxidative stress in red blood cells Biomed Pap Med Fac Univ Palacky Olomouc Czech Repub. 2011;155(2):131136. DOI 10.5507/bp.2011.027.

49. Clemens MR, Waller HD. Lipid peroxidation in erythrocytes. Chem Phys Lipids 1987;45:251-68I.

50. Villanueva I, Alva-Sánchez C, Pacheco-Rosado J. The role of thyroid hormones as inductors of oxidative stress and neurodegeneration. Oxid Med Cell Longev. 2013;Article ID 218145. 